\title{
Analysis of Ocular Surface Temperature in Patients with Dry Eye
}

\author{
ALI ABUSHARHA, Ph.D. \\ The Department of Optometry, College of Applied Medical Sciences, King Saud University, P.O. Box 10219, Riyadh 11433, \\ Saudi Arabia
}

\begin{abstract}
Background: Ocular surface temperature (OST) has been widely investigated using the principle of recording the infrared radiation (IR) emitted by the ocular surface.OST changes have been reported in different ocular diseases, such as glaucoma, choroidal abnormalities, and dry eye.
\end{abstract}

Aim of Study: The objective of this study was to investigate the relationship between tear film evaporation rate and ocular surface temperature in patients with mild to moderate dry eye.

Material and Methods: Twenty-five patients with dry eye (average age, $42.61 \pm 9.77$ years) were recruited for this study. An infrared camera was used to measure the ocular surface temperature. The geometric center of the cornea was estimated manually by drawing a circle with approximately 4-mm diameter at its center, and the mean temperature of this circle area was calculated. Thermal images of the ocular surface were continuously recorded for 60 seconds at a frame rate of $30 \mathrm{~Hz}$. The tear film evaporation rate was determined using a handheld closed chamber evaporimeter. Three measurements were obtained; then, the average value was calculated.

Results: The measured ocular surface temperature was lower in the dry eye group $\left(33.74 \pm 0.058^{\circ} \mathrm{C}\right)$ than in the control group $\left(33.92 \pm 0.57^{\circ} \mathrm{C}\right)$. The tear evaporation rate was significantly greater in patients with dry eye $(77.37 \pm 23.07)$ than in the control group $\left(49.53 \pm 15.36 \mathrm{~g} / \mathrm{m}^{2} / \mathrm{h}\right)$.

Conclusion: This study demonstrates that the ocular surface of patients with dry eye is cooler compared to that of healthy individuals $\left(<0.2^{\circ} \mathrm{C}\right)$. The significantly increased tear film evaporation rate may explain the reduction in ocular surface temperature (OST) among patients with dry eye.

Key Words: Ocular surface temperature - Tear film evaporation rate - Dry eye syndrome.

\section{Introduction}

DRY eye is a multifactorial disorder of tear film and ocular surface that can lead to complications, including ocular discomfort, visual disturbance, ocular surface damage, and ocular inflammatory events [1]. Dry eye is one of the most common reasons for seeking medical care. It adversely

Correspondence to: Dr. Ali Abusharha,

E-Mail: aabusharha@ksu.edu.sa affects the quality of life of patients and represents an economic burden due to the cost of health care and loss of work productivity [2].

Evaporative dry eye is one of the main subtypes of dry eye disease that is caused by excessive water loss from the ocular surface [1]. An increase in tear film evaporation can lead to tear hyperosmolarity and instability, which play an important role in the core mechanism of dry eye [3]. Since 1980, a number of measuring techniques have been utilized to evaluate the tear film evaporation rate. Many studies have reported an elevated evaporation rate in both aqueous-deficient and evaporative dry eye [4-6]. Alterations in tear film evaporation rate could be due to meibomian gland dysfunction, eyelid disorders, or low blink rate [7].

Ocular surface temperature (OST) has been widely investigated using the principle of recording the infrared radiation (IR) emitted by the ocular surface. Central corneal temperature ranges between $32.8^{\circ} \mathrm{C}$ and $35.4^{\circ} \mathrm{C}[8]$. Another study that utilized the principle of IR thermography has reported an OST range of $33-36^{\circ} \mathrm{C}$ [9]. OST can be influenced by many internal and external factors, such as room temperature, air flow, age, and ocular abnormalities

OST changes have been reported in different ocular diseases, such as postherpetic neuralgia, glaucoma, choroidal abnormalities, and dry eye [11].IR thermography has been used to analyze the OST during or after ocular surgical procedures. A higher OST has been found during and after photorefractive keratectomy and cataract surgery $[\mathbf{1 2 , 1 3}]$

Changes in the OST and tear film of patients with dry eye have been reported. Morgan et al., used IR thermography to record the distribution of OST. The mean central OST of patients with dry eye was higher $\left(32.38^{\circ} \mathrm{C}\right)$ than that of normal subjects $\left(31.94^{\circ} \mathrm{C}\right)[14]$. In contrast, another study 
reported that patients with dry eye have lower OST and faster cooling rate. It has been shown that patients with dry eye have an average central OST of $34.13^{\circ} \mathrm{C}$ compared to $34.77^{\circ} \mathrm{C}$ in normal subjects [15].

The objective of this study was to investigate the relationship between tear film evaporation rate and OST in patients with mild to moderate dry eye.

\section{Patients and Methods}

All study procedures were reviewed and approved by the College of Applied Medical Sciences Ethics Committee, King Saud University. The study was conducted in agreement with the tenets of the Declaration of Helsinki, and subjects provided written informed consent.

Patients with mild to moderate dry eye were recruited from optometry clinics at the College of Applied Medical Sciences, King Saud University. The patients were included in the study if they have a break up time $<5$ s (Oculus Keratograph 4), [16] Schirmer test $<10 \mathrm{~mm}$ per $5 \mathrm{~min}$, and Ocular Surface Disease Index score $>13$ [17]. The subjects were excluded if they wear contact lenses or had any ocular or systemic conditions that could influence the tear film. Twenty-five patients (average age, $42.61 \pm 9.77$ years) with dry eye were recruited in this study. Twenty-five normal, age-matched, healthy volunteers with no evidence of dry eye were recruited as controls.

All test procedures were performed in a controlled environment at $20.96 \pm 0.46^{\circ} \mathrm{C}$ and $42 \pm 2 \%$ humidity. For the purpose of environmental adaptation, the subjects were requested to set in the room for $10 \mathrm{~min}$ before starting the investigations for OSTand evaporation rate.

\section{Thermography:}

An infrared camera was used to measure the OST (FLIR T1010, FLIR Systems, Surrey, UK). The camera is self-calibrating comes with a high definition detector (focal plane array, uncooled microbolometer) with resolution of $1024 \times 768$ pixels and image frequency of $30 \mathrm{~Hz}$ and can detect a temperature range between -40 and $+150^{\circ} \mathrm{C}$. The geometric center of the cornea was estimated manually by drawing a circle of approximately 4-mm diameter at its center, and the mean temperature of this circle area was calculated (Fig. 1). Thermal images of the ocular surface were continuously recorded for $60 \mathrm{~s}$ at a frame rate of $30 \mathrm{~Hz}$. Measurements obtained during and immediately post-blink were excluded. All temperature measurements were then exported to an Excel spreadsheet and 600 thermal values were selected with exclusion of the reading recorded immediately after blink.

\section{Evaporimetry:}

The tear film evaporation rate was determined using a handheld closed chamber evaporimeter (Vapo Meter, Delfin Technologies, Kuopio, Finland) [6]. This handheld portable device was fitted to a swimming goggle to measure the evaporation rate of the eye and surrounding skin. Two readings were taken; the first was taken with eyes open, and the second was obtained with eyes closed, which represent the evaporation rate from the surrounding skin only. Then, the second reading was subtracted from the first reading to calculate the magnitude of water (tear) loss from the ocular surface. Three measurements were obtained; then, the average value was calculated.

\section{Statistical analysis:}

All data were statistically analyzed using IBM SPSS Statistics (IBM corporation, Somers, NY, USA). First, a test of normality was carried out using Kolmogorov-Smirnov test. Normally distributed data were compared using Independent Sample $p$-test. Non-normally distributed data were compared using Mann-Whitney U test.

\section{Results}

The mean and standard deviation of OSTsand evaporation rates measured in the dry eye group and control group are shown in Table (1). Although the measured OSTs were lower in the dry eye group $\left(33.74 \pm 0.058^{\circ} \mathrm{C}\right)$ compared with the control group $\left(33.92 \pm 0.57^{\circ} \mathrm{C}\right)$, the parametric statistical tests showed no significant difference in OST between the two groups ( $p=0.26$ ) (Fig. 2).

A boxplot of tear film evaporation rate is shown in Fig. (3). Unlike OST, the tear evaporation rate in the dry eye group $\left(77.37 \pm 23.07 \mathrm{~g} / \mathrm{m}^{2} / \mathrm{h}\right)$ was significantly higher than that in the control group $\left(49.53 \pm 15.36 \mathrm{~g} / \mathrm{m}^{2} / \mathrm{h}\right)$. Spearman's Rho test showed no statistically significant correlation between OST and tear evaporation in both study groups.

Table (1): The mean and standard deviation of ocular surface temperature and evaporation rate measured in control and patients with dry eye.

\begin{tabular}{lcc}
\hline & Control & Dry eye \\
\hline Ocular surface temperature $\left({ }^{\circ} \mathrm{C}\right)$ & $33.92 \pm 0.57$ & $33.74 \pm 0.058$ \\
Tear Evaporation rate $\left(\mathrm{g} / \mathrm{m}^{2} / \mathrm{h}\right)$ & $49.53 \pm 15.36$ & $77.37 \pm 23.07$ \\
\hline
\end{tabular}




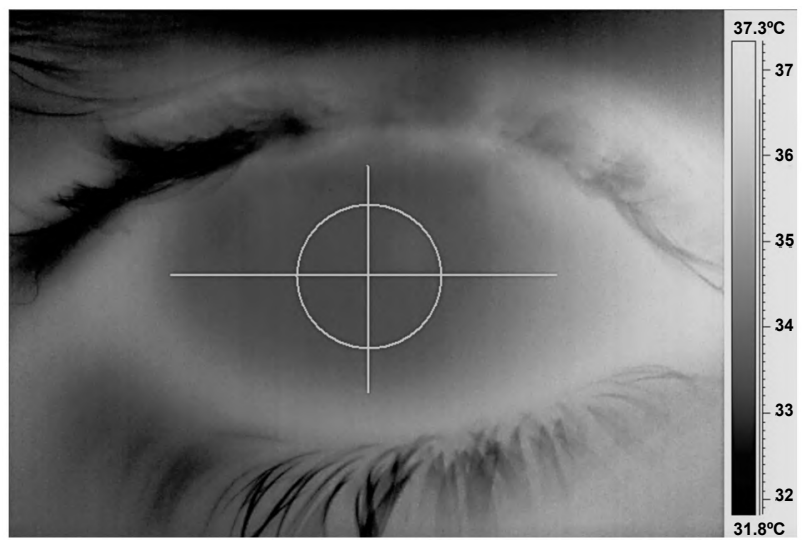

Fig. (1): Ocular thermogram displayed on PC screen with a circle of approximately $4 \mathrm{~mm}$ represents the estimated geometric center of the cornea.

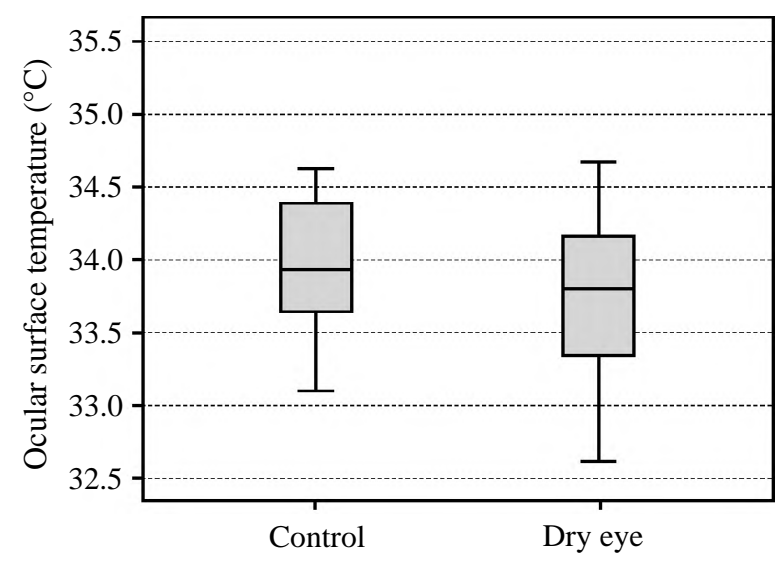

Fig. (2): Side-by-side boxplot for the ocular surface temperature of study and control groups.

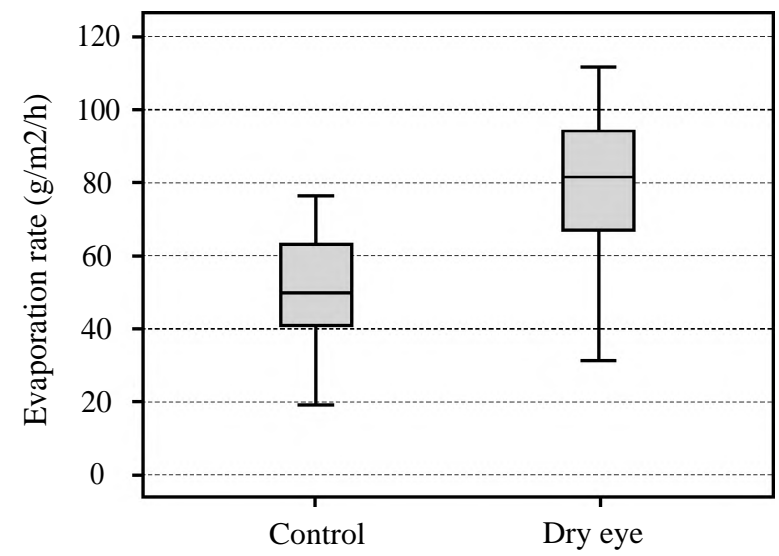

Fig. (3): Side-by-side boxplot for the evaporation rate of study and control groups.

\section{Discussion}

Numerous contact and noncontact techniques have been developed to measure the OST. Contact techniques, such as mercury-in-glass thermometers, thermistor probes, and liquid crystal contact lenses, have been used to measure the OST $[\mathbf{9 , 1 8}]$.
The first infrared measurement of OST was conducted by Mapstonein 1968. In the 1990s, Morgan et al., used second-generation infrared cameras to record the distribution of ocular temperatures [14]. Unlike infrared thermometers that provide a single temperature measurement, infrared thermograms record the distribution of temperatures using the IR emitted from the ocular surface. Infrared thermo-cameras utilize either scanning array or focal plane array photo sensitive detectors to produce a digital infrared thermograph.

OST measurement received considerable attention due to its well-established correlation with many ocular diseases, such as dry eye, carotid artery stenosis, unilateral exophthalmos, Graves' ophthalmopathy, bulbar conjunctival hyperemia, diabetic retinopathy, central retinal vein occlusion, glaucoma, and inflammation of the lacrimal drainage system [19,20,21]. Environmental factors, such as air flow and ambient temperature, could also influence the OST. A previous study has reported that the central corneal temperature decreased from $34.72 \pm 1.6^{\circ} \mathrm{C}$ to $31.9 \pm 1.6^{\circ} \mathrm{C}$ when the room temperature decreased by $4{ }^{\circ} \mathrm{C}$ [22]. Another study reported a reduction of $4^{\circ} \mathrm{C}$ in OST when the ambient temperature decreased from $25{ }^{\circ} \mathrm{C}$ to $5^{\circ} \mathrm{C}$ [23].

In this study, infrared thermal imaging was utilized to monitor the OST of patients with dry eye. Patients with dry eye $\left(33.74 \pm 0.058^{\circ} \mathrm{C}\right)$ had lower central corneal temperature than the control group $\left(33.92 \pm 0.57^{\circ} \mathrm{C}\right)$. This is in agreement with previous studies that reported a lower corneal temperature by $0.2^{\circ} \mathrm{C}$ and faster cooling rate in patients with dry eye [24].

Craig JP et al., reported a greater difference in OST between patients with dry eye and normal subjects, where the OST was $0.58^{\circ} \mathrm{C}$ lower in patients with dry eye [25].

The observed reduction in corneal temperature could be attributed to the increase in tear evaporation rate in patients with dry eye. In this study, patients with dry eye showed a higher tear film evaporation rate. This correlates well with previous studies, suggesting that patients with aqueous or evaporative dry eye have higher tear film evaporation rates [26]. Excessive tear evaporation can be caused by many internal or external factors. One of the most common reasons for the increase in tear film evaporation is meibomian gland dysfunction, as the lipid layer works to decrease surface tension and minimize tear evaporation [27] 
In contrast, studies have reported a higher OST in patients with dry eye. Morgan et al., suggested that patients with dry eye have a greater corneal temperature compared to normal subjects. The mean OST of patients with dry eyewas $0.44^{\circ} \mathrm{C}$ lower [14]. Another study has shown that although patients with dry eye showed a faster reduction in OST following eye opening, they showed an increased OST [28]. A correlation between OST and ocular blood flow is well-documented. Moreover, an increase of $0.5^{\circ} \mathrm{C}$ in ocular temperature has been noted in subjects with bulbar conjunctival hyperemia [29]. Dry eye is associated with signs of inflammation and eyelid and conjunctival hyperemia; therefore, the elevated OST seen in patients with dry eye could be caused by an increased ocular blood flow.

However, the differences in the reports could also be due to the use of different measuring techniques or differences in environmental temperature range over, which OST was observed. Moreover, a possible explanation for these conflicting results may be the variety of anatomical localization methods that were used for OST measurement.

\section{Conclusion:}

This study demonstrates that the ocular surface of patients with dry eye is cooler compared to that of healthy individuals $\left(<0.2^{\circ} \mathrm{C}\right)$. The significantly increased evaporation rate of tear film noted in this study may explain the reduction in OST among patients with dry eye. IR thermography can potentially provide clinicians with a readily available method to monitor ocular surface abnormalities.

\section{Acknowledgements:}

The authors are grateful to the Deanship of Scientific Research, King Saud University for funding through Vice Deanship of Scientific Research Chair.

Disclosure: The authors report no conflicts of interest in this work.

\section{References}

1- CRAIG J.P., et al.: TFOS DEWS II definition and classification report. The Ocular Surface, 15 (3): p. 276-283, 2017.

2- STAPLETON F., et al.: TFOS DEWS II epidemiology report. The ocular surface, 15 (3): p. 334-365, 2017.

3- FOULKS G.N.: DEWS Report. The Ocular Surface, 5 (2): p. 65-66, 2007

4- PETZNICK A., et al.: Repeatability of a new method for measuring tear evaporation rates. Optometry and Vision Science, 90 (4): p. 366-371, 2013.

5- ROHIT A., et al.: Validating a new device for measuring tear evaporation rates. Ophthalmic and Physiological Optics, 34 (1): p. 53-62, 2014.
6- ABUSHARHA A.A., et al.: Repeatability and Reproducibility of Tear Film Evaporation Rate Measurement using a new Closed-Chamber Evaporimeter. The Open Ophthalmology Journal, 15 (1), 2021.

7- CHHADVA P., GOLDHARDT R. and GALOR A.: Meibomian gland disease: The role of gland dysfunction in dry eye disease. Ophthalmology, 124 (11): p. S20-S26, 2017.

8- EFRON N., YOUNG G. and BRENNAN N.A.: Ocular surface temperature Current Eye Research, 8 (9): p. 901906, 1989

9- PURSLOW C. and WOLFFSOHN J.S.: Ocular surface temperature: A review. Eye Contact Lens, 31 (3): p. 117 23, 2005.

10- TAN J.H., et al.: Infrared thermography on ocular surface temperature: A review. Infrared Physics \& Technology, 52 (4): p. 97-108, 2009.

11- TAN J.H., et al.: Study of normal ocular thermogram using textural parameters. Infrared Physics \& Technology, 53 (2): p. 120-126, 2009.

12- JU R.-H., et al., Changes in ocular surface status and dry eye symptoms following femtosecond laser-assisted cataract surgery. International Journal of Ophthalmology, 12 (7): p. 1122, 2019.

13- LECA R., et al.: Study of the corneal temperature variation during photo-refractive procedures. Investigative Ophthalmology \& Visual Science, 62 (8): p. 2318-2318, 2021.

14- MORGAN P.B., TULLO A.B. and EFRON N.: Infrared thermography of the tear film in dry eye Eye, 9: p. 615$618,1995$.

15- KAMAO T., et al.: Screening for dry eye with newly developed ocular surface thermographer. American Journal of Ophthalmology, 151 (5): p. 782-791. e1, 2011.

16- BEST N., DRURY L. and WOLFFSOHN J.: Clinical evaluation of the Oculus Keratograph. Contact lens and anterior eye, 35 (4): p. 171-174, 2012.

17- SCHIFFMAN R.M., et al.: Reliability and validity of the ocular surface disease index. Archives of Ophthalmology, 118 (5): p. 615-621, 2000.

18- TAN J.H., NG E. and ACHARYA U.R.: Evaluation of tear evaporation from ocular surface by functional infrared thermography. Medical Physics, 37 (11): p. 6022-6034, 2010.

19- CHANDRASEKAR, B., et al.: Ocular surface temperature measurement in diabetic retinopathy. Experimental Eye Research, p. 108749, 2021.

20- SODI A., et al.: Ocular surface temperature in central retinal vein occlusion: Preliminary data. European Journal of Ophthalmology, 17 (5): p. 755-759, 2007.

21- GARCÍA-PORTA N., et al.: Characterization of the ocular surface temperature dynamics in glaucoma subjects using long-wave infrared thermal imaging. JOSA A, 36 (6): p. 1015-1021, 2019.

22- SCHWARTZ B.: Environmental Temperature and the Ocular Temperature Gradient. Arch. Ophthalmol., 74: p. 237-43, 1965. 
23- ABUSHARHA A.A., PEARCE E.I. and FAGEHI R.: Effect of Ambient Temperature on the Human Tear Film. Eye \& contact lens, 2015.

24- FUJISHIMA H., et al.: Corneal temperature in patients with dry eye evaluated by infrared radiation thermometry. British Journal of Ophthalmology, 80 (1): p. 29-32, 1996.

25- CRAIG J.P., et al.: The role of tear physiology in ocular surface temperature. Eye, 14: p. 635-641, 2000.

26- WILLCOX M.D., et al.: TFOS DEWS II tear film report. The Ocular Surface, 15 (3): p. 366-403, 2017.
27- GEERLING G., et al.: The international workshop on meibomian gland dysfunction: report of the subcommittee on management and treatment of meibomian gland dysfunction. Investigative ophthalmology \& visual science, 52 (4): p. 2050-2064, 2011.

28- MORGAN P., TULLO A. and EFRON N.: Ocular surface cooling in dry eye-a pilot study. Journal of the British Contact Lens Association, 19 (1): p. 7-10, 1996.

29- EFRON N., et al.: Temperature of the hyperemic bulbar conjunctiva. Current Eye Research, 7 (6): p. 615-618, 1988.

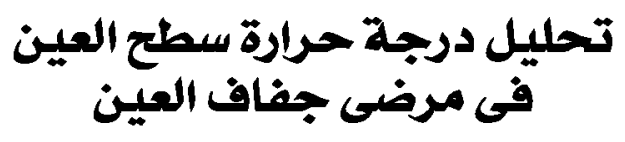

تشكل الطبقة الدمعية للعين خط الدفاع الأول لسطح العين وتقدم عدداً من الوظائف ومن أهمها ترطيب سطح العين وتقديم الحماية والتغذية

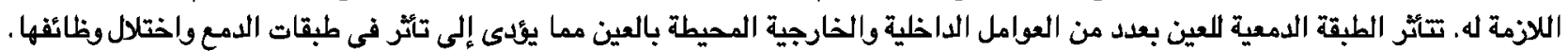

الخلفية: يعتبر قياس درجة حرارة سطح العين من الوسائل الصديثة التى تستخدم مؤخراً لمراقبة صحة العين في عدد من الصالات المرضية

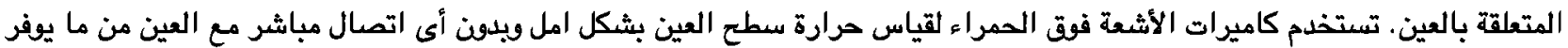

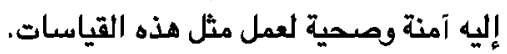

الهدف من البحث: الهدف من الدراسة الحالية هى مراقبة درجة حرارة سطح العين وعلاقتها بمعل تبخر الدمع في الأثخاص الذين يعانون

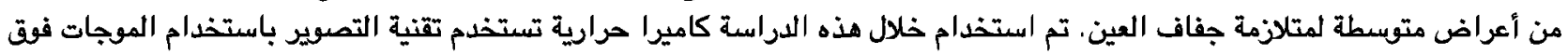

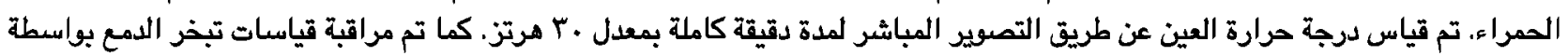
جهاز قياس تبخر الجلد بعد أن تم تعديله بتركيب أطار نظارة واقية حهل العين لقياس التبخر الناتج من سطع العين.

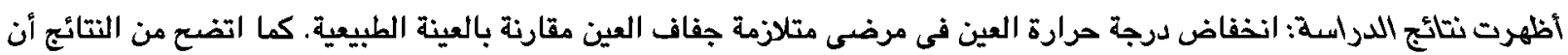

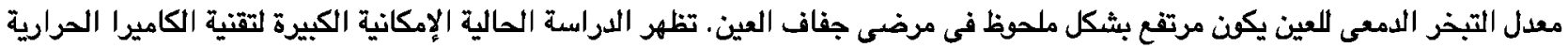
لمراقبة ومتابعة أمراض سطع العين من خلال تتبع أنماط التغيير في حرارة سطع مرئ العين. 